\title{
Organization of Partner Knowledge: Relationship Outcomes and Longitudinal Change
}

\author{
Carolin J. Showers \\ Virgil Zeigler-Hill \\ University of Oklahoma
}

This study examined the association between organization of knowledge about a romantic partner (partner structure) and relationship status (ongoing or ended) 1 year later. Ironically, partner structures that were associated with more positive feelings about one's partner at Time 1 were associated with greater rates of breakup by Time 2. These results are interpreted in terms of the vulnerability of compartmentalized partner structures to shifts in the salience of negative beliefs and the hypothesized difficulty of maintaining integrative structures for an extended period of time. Change in partner structure during 1 year's time was consistent with the predictions of the dynamic model that evaluative integration should increase when negative beliefs become salient. Such change (which may represent a transient shift) was associated with couples' longevity when relationship conflict was low, supporting the view that integration reflects a struggle with negative attributes that may or may not be successful.

Keywords: partner structure; relationship resilience; cognitive structure; self-concept

W hen thinking about romantic relationships, a major concern of layperson and expert alike is how best to handle the flaws one perceives in a romantic partner. Researchers have identified strategies such as focusing one's attention on positive characteristics (Murray, Holmes, \& Griffin, 1996a), making positive attributions for bad behaviors (Bradbury \& Fincham, 1990), voicing concern, or simply remaining loyal and hoping for the best (Rusbult, Verette, Whitney, Slovik, \& Lipkus, 1991). Increasingly, this literature has focused on long-term outcomes of relationships, testing whether strategies that smooth the course of the relationship in the short term pay off over an extended period of time (e.g., Gottman \& Krokoff, 1989; Huston, Caughlin, Houts, Smith, \& George, 1996; Karney \& Bradbury, 1995). A related consideration is the extent to which successful partners show flexibility in their styles of responding to their significant other, adjusting their strategies in response to factors such as the level of external stress, the severity of the transgression, feelings of intimacy or commitment, or the length of the relationship (cf. Holmes \& Murray, 1996).

One component of a person's strategies for responding to a partner's flaws may be the cognitive organization of beliefs about that person. An underlying cognitive structure may determine which subset of beliefs are accessible in any given context, affecting an individual's response. In particular, evaluative organization (i.e., the way in which positive and negative beliefs are organized) may be an important feature of these knowledge structures (Showers, 1995, 2000; Showers \& Kling, 1996a).

Drawing on studies of how people organize positive and negative beliefs about the self, Showers and Kevlyn (1999) examined whether the organization of positive and negative beliefs about a romantic partner was associated with feelings of liking and loving. Here, organization refers to the category structure of knowledge or beliefs, which can be described as evaluatively compartmentalized or evaluatively integrative. The model assumes that beliefs about a romantic partner are organized into a set of categories that represent different aspects of that person or their life, such as different roles, contexts, states, traits, or experiences. Within each category are the specific beliefs associated with that aspect. In

Authors' Note: This research was supported by funds from the University of Wisconsin Graduate School. We thank Victoria Clark, Patrick McMahon, Tara Murrish, and Rebecca Philipp for their assistance in data collection and data coding. We appreciate the special contributions of David Amodio, Suzanne Kevlyn, and Kim Manoil. Correspondence concerning this article should be addressed to Carolin J. Showers, Department of Psychology, University of Oklahoma, Norman, OK 73019; e-mail: cshowers@ou.edu.

PSPB, Vol. 30 No. 9, September 2004 1198-1210 DOI: $10.1177 / 0146167204264077$

(C) 2004 by the Society for Personality and Social Psychology, Inc. 
a compartmentalized structure, the specific beliefs associated with any aspect (i.e., category) tend to be either uniformly positive or uniformly negative. For example, a person might represent a partner's "parenting" aspect as "available," "involved," "playful," "thoughtful," and "committed." In contrast, in an evaluatively integrative structure, both positive and negative attributes tend to be associated with each category. For example, a partner's "travel" aspect might be represented as "enthusiastic," "disorganized," "adventurous," "irritable," "controlling," and "energetic."

The findings of Showers and Kevlyn (1999) supported the basic model of compartmentalization (e.g., Showers, 2000). When a person had a mostly positive perception of the partner's attributes, a compartmentalized structure of beliefs was correlated with greater liking and loving than was an integrative structure. According to the model, a compartmentalized structure minimizes access to negative attributes when the most salient compartments are positive ones. However, when the partner has many important or salient negative attributes, then salient negative compartments should have a negative impact on feelings for the partner. Under these circumstances, an integrative partner structure was associated with relative liking and loving. The integrative structure should bring both positive and negative attributes to mind, thereby minimizing the impact of important negative attributes that are difficult to avoid.

The terms "positive compartmentalized" and "negative compartmentalized" have been used to distinguish knowledge structures in which positive compartments or negative compartments, respectively, are likely to be most salient or important (and, therefore, likely to dominate the person's overall attitude toward the partner). Integrative categories also can be identified as relatively positive or negative at the category level, even though the attributes in these categories are mixed. In keeping with the basic model (and the findings of Showers and Kevlyn, 1999), the knowledge structures associated with relatively positive attitudes toward self or partner in the short term are positive compartmentalized or negative integrative (Showers \& Zeigler-Hill, 2003). When positive beliefs are most important or salient, positive compartmentalization isolates negative beliefs in rarely activated negative compartments, essentially "sweeping them under the rug"; when negative beliefs are most important or salient, negative integration, which brings a mixture of positive and negative beliefs to mind, is preferable to activating pure negative compartments.

The present study examines longer term relationship outcomes associated with different types of partner structures, as well as how those structures may change with relationship stress. Although the cognitive model of evaluative organization is the same for partner knowledge and self-knowledge, the investigation of partner knowledge is especially interesting in several respects. First, because college students' relationships are relatively new (typically less than 5 years old), attitudes about a romantic partner (i.e., feelings of liking and loving), as well as the associated knowledge structures, may be especially likely to change with time (cf. Cate, Levin, \& Richmond, 2002). Second, in contrast to longitudinal studies of self, romantic relationships that are followed over time have concrete outcomes-they are either ongoing or they end.

The present study looks first at the association between the structure of knowledge about a romantic partner and the status of the relationship (ongoing or ended) 1 year later. Although one might expect the partner structure (positive compartmentalization) associated with the most positive feelings for the partner at Time 1 to be correlated with ongoing status at Time 2, previous studies suggest that compartmentalized structures may be vulnerable to shifts in the salience or perceived importance of negative attributes. Showers and Kling (1996b) found that both positive and negative compartmentalized individuals were slow to recover from a sad mood, presumably because the mood activated their negative compartments and flooded them with negative self-beliefs. Compartmentalization also has been associated with high day-to-day variability in self-esteem in narcissists (Rhodewalt, Madrian, \& Cheney, 1998), presumably reflecting an exaggerated response to daily events that depended on whether positive or negative compartments were primed. Hence, an alternative hypothesis is that positive-compartmentalized partner structures may be vulnerable to shifts in the salience of a partner's negative attributes during the course of a year, leading to high rates of breakup. Positiveintegrative structures, associated with less rosy feelings in the short term, may be more realistic in the long term and may inoculate individuals against negative characteristics that gradually emerge in their partners. Consistent with this alternative hypothesis, Murray and Holmes (1999) found that individuals who possessed more compartmentalized views of the positive and negative attributes of their partners were more likely to dissolve their relationships within 1 year. This result remained when controlling for content of the representation, well-being of the relationship, and positive illusions about the partner.

Among individuals who described their partners in relatively negative terms, a negative integrative structure at Time 1 was associated with relatively positive feelings for the partner, presumably because integration maintains access to positive beliefs even when negative attributes are salient (Showers \& Kevlyn, 1999). However, 
Showers and Kling (1996b) suggested that integrative structures may require considerable cognitive and emotional effort to maintain (see Showers, 2002, or Showers, Limke, and Zeigler-Hill, 2004, for an extended discussion of this issue). If integration reflects an individual's struggle with negative beliefs about a partner, feelings for the partner may be enhanced in the short run, but this strategy may wear itself out in time. In other words, integration may be an effective short-term strategy for maintaining a positive attitude toward a partner with many flaws, even though it is ultimately associated with high rates of breakup. Negative-compartmentalized structures, although associated with negative attitudes toward the partner, may characterize relatively stable relationships in which important flaws are isolated to the extent possible.

A second aim of this study was to examine change in the structure of partner knowledge. Predictions for change are derived from the dynamic model of selforganization (Showers, 2000, 2002). According to this model, people tend to maintain positive compartmentalized knowledge structures as a baseline because most of their beliefs (about self or partner) are positive and because of the ease, efficiency, and natural tendency to use valence as a basis of categorization (cf. Bower, 1981; Fiske, 1982; Halberstadt \& Niedenthal, 1997; Osgood, 1969). However, when negative attributes (of self or partner) are made salient, often by stressful events, people may shift to the more effortful integrative structures as they struggle to minimize the impact of salient negative beliefs. When the stress subsides, many people may recompartmentalize their knowledge structures, reverting to the style of organization that minimizes access to negative attributes. This dynamic process is illustrated on the right side of Figure 1. A less adaptive response to salient negative beliefs is shown on the left side of the figure. Individuals who do not shift to an integrative structure may simply move from positive compartmentalization to negative compartmentalization as their negative attributes and self-aspects come to be seen as the important ones.

In college student relationships, new information about the partner (some of it negative) may be learned during the course of 1 year. In addition, some relationships may experience high levels of conflict and the salience of negative beliefs about the partner may change. According to the dynamic model, people should shift to an integrative style of organization as they struggle to mitigate the impact of newly salient negative beliefs. This shift should be especially pronounced for individuals who are experiencing relationship conflict or stress. Evidence for this kind of shift toward integration in the case of the self was obtained in a study of college-age women selected for high and low levels of body

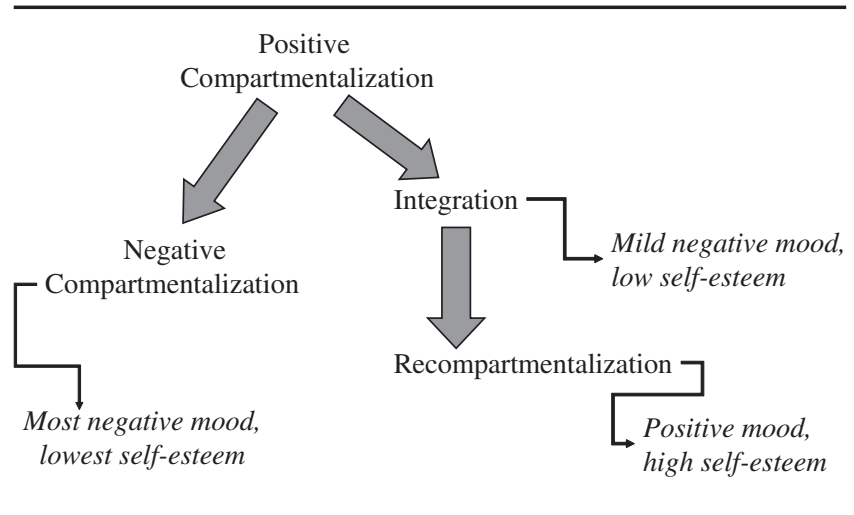

Figure 1 Dynamic model of self-organization. SOURCE: Showers (2002).

dissatisfaction and/or disordered eating (McMahon, Showers, Rieder, Abramson, \& Hogan, 2003). Those women who were most well adjusted (i.e., reported the least negative mood) had positive compartmentalized baseline self-structures yet shifted to an integrative style of thinking when attention was focused on their most negative characteristic.

The dynamic model suggests that change in partner structure may be adaptive, that is, it may help to maintain consistent attitudes by minimizing the impact of newly discovered beliefs and stabilizing feelings for the partner. However, shifts toward integration also may reflect an individual's struggle with negative beliefs about their partner, a strategy that will not necessarily succeed. The correlation between change in partner structure and relationship outcomes at Time 2 may provide some indication as to whether structural change is associated with the maintenance of positive feelings for the partner or with deteriorating relationship outcomes.

\section{METHOD}

\section{Overview}

Individuals who had participated in Showers and Kevlyn's (1999) study of the organization of knowledge about a romantic partner were followed up 1 year later. They participated in a 10-min phone interview that assessed whether their relationship was ongoing or had ended and included several relationship measures (including an assessment of relationship problems and conflicts during the past year). These individuals also were invited to participate in a laboratory session in which they repeated the card-sorting task used previously to assess the structure of their partner knowledge.

\section{Participants}

One hundred eighteen introductory psychology students completed two laboratory sessions at Time 1 in 
exchange for bonus points toward their grade. To be eligible for the study, all participants had to be in an ongoing, exclusive romantic relationship for 3 months or more. Although it was not a criterion for inclusion, all participants were in heterosexual relationships. One year later, 111 of these individuals participated in a 10min phone interview about the current status and quality of their relationship and were invited to participate in an additional laboratory session. Eighty-five individuals returned for the Time 2 laboratory session and were paid $\$ 15$. $t$ tests were conducted to compare the 33 individuals who participated at Time 1 but not at Time 2 to the 85 participants at Time 2 on the following background variables, but no differences were found, $t \mathrm{~s}(116)<.70, n s$; gender, $66 \%$ female; age, $M=19.6$ years; and length of relationship at Time $1, M=24.8$ months.

\section{Measures}

\section{CARD-SORT DESCRIPTION OF PARTNER}

A card-sorting task provided measures of the content and structure of knowledge about one's partner. Showers's (1992; Showers \& Kling, 1996b) version of this task is adapted from Linville $(1985,1987)$. Participants were given a deck of 40 cards, each containing an adjective that might be used to describe one's partner. There were 20 positive and 20 negative attributes.

Participants were asked to sort the cards into groups to generate a description of their relationship partner. They were told, "Your task is to think of the different aspects of your partner or his or her life and then form groups of traits that go together, where each group of traits describes an aspect of your partner or his or her life." Participants could form as many groups as they needed, with as many or as few attributes as fit each one. They could use the same attribute in more than one group and they did not have to use attributes that did not describe their partner. They were given 25 min to work on this task (see Showers and Kevlyn, 1999, for complete instructions). Participants generated 6.58 groups on average, with 7.99 attributes in each group. The appendix presents sample card sorts from actual participants in this study.

\section{PARTNER KNOWLEDGE MEASURES}

Partner negativity. This is the proportion of attributes in the partner card sort that are negative, that is, the number of negative attributes divided by the total number of attributes used. The positive or negative valence of the attributes was established by independent raters (Showers, 1992). This is a measure of the content of the partner description. It also serves as an indicator of whether compartmentalized organization is positive compartmentalized or negative compartmentalized.
Compartmentalization (phi). The measure of compartmentalization is a phi coefficient (Cramer, 1974; Everitt, 1977) based on a chi-square statistic. It compares the frequencies of positive and negative attributes in each group of the card sort to those that would be expected given the proportion of negative attributes in the card sort as a whole. A frequency table is constructed that contains as many columns as there are groups in the card sort, and two rows (number of positive attributes and number of negative attributes). The observed frequency values are obtained from the card sort. The expected frequencies are generated as follows: If the card sort contained 30\% negative attributes overall and the first group contained 10 attributes, then the expected frequencies for that group would be 7 positive attributes and 3 negative attributes. These expected frequencies represent chance values for organizing positive and negative attributes without regard for their valence. The chisquare statistic computed using these expected and observed frequencies is normalized by dividing by the number of attributes in the sort $(N)$.

$$
\text { Cramer's } \Phi=\sqrt{ }\left(\chi^{2} / N\right)
$$

Phi can range from 0 to 1 , where 0 represents a perfectly random sort and 1 represents a perfectly compartmentalized sort. Phi is not calculated for card sorts that contain fewer than two negative attributes. The sample card sorts in the appendix illustrate high compartmentalization (Panel A: phi $=.91$ ) and low compartmentalization (Panel B: phi $=.48$ ) of partner knowledge.

\section{RELATIONSHIP VARIABLES}

Relationship conflict. Ten questions included in the phone interview were derived from the Relationship Problem Scale (Riggs, 1993) and the Conflict-Negativity Subscale of the Themes of Relationship Development Scale (Braiker \& Kelley, 1992). Because of time constraints in the phone interview, one item was constructed to represent each of the seven subscales of the Relationship Problem Scale. Participants rated the extent to which each of the following was a problem during the past year: poor communication, fighting, jealousy, amount of time spent together, different interests, problems with friends or family, and problems with alcohol or drugs. The remaining 3 items were selected from the 5 items on the Conflict-Negativity Subscale: arguing with each other, feelings of anger or resentment toward your partner, and feelings of dissatisfaction or frustration toward your partner. The reliability coefficient for these 10 items was $\alpha=.81(n=110)$.

Attitudes toward partner. In their analysis of the association between partner structure and overall feelings for the partner at Time 1, Showers and Kevlyn (1999) used Rubin's (1970) Liking and Loving Scales as a measure of 
TABLE 1: Intercorrelations and Descriptive Statistics for Measures of Partner Knowledge at Times 1 and 2, Months in Relationship, and Relationship Conflict

\begin{tabular}{|c|c|c|c|c|c|c|c|}
\hline & 1 & 2 & 3 & 4 & 5 & 6 & 7 \\
\hline 1. Partner negativity (Time 1) & - & & & & & & \\
\hline 2. Partner structure (Time 1) & -.03 & - & & & & & \\
\hline 3. Months in relationship & -.04 & -.05 & - & & & & \\
\hline 4. Relationship conflict & $.24 *$ & -.16 & .01 & - & & & \\
\hline 5. Partner negativity (Time 2) & $.41 * *$ & -.06 & .06 & $.54 * * *$ & - & & \\
\hline 6. Partner structure (Time 2) & .00 & $.53 * * *$ & .20 & -.05 & .08 & - & \\
\hline 7. Change in partner structure & -.01 & $-.49 * * *$ & .17 & .06 & .15 & $.49 * * *$ & - \\
\hline$M$ & $.27^{\mathrm{a}}$ & .68 & $2.81^{\mathrm{a}}$ & 1.46 & $.31^{\mathrm{a}}$ & .69 & .00 \\
\hline$S D$ & .13 & .22 & .74 & .56 & .15 & .21 & .19 \\
\hline Skewness & .70 & -.36 & -.31 & .23 & .42 & -.46 & -.64 \\
\hline
\end{tabular}

NOTE: $n=90$ for variables 1 to $4 ; n=65$ for variables 5 to 7 . These are pairwise correlations.

a. The measures of partner negativity (proportion of negative attributes in the card sort) were arcsine transformed, and months in relationship was $\log$ transformed for the computation of correlations and skew. Ms and SDs shown are transformed values. Actual values: partner negativity at Time $1, M=.26, S D=.12$; partner negativity at Time $2, M=.30, S D=.14$; months in relationship, $M=21.25, S D=14.05$. The measure of partner structure is phi, the index of compartmentalization, scored such that greater values correspond to a more compartmentalized structure.

$* p<.05 . * * p<.01 . * * * p<.001$.

feelings for the partner. The study also included the Relationship Assessment Scale (Hendrick, 1988) as a measure of relationship satisfaction. In the present study, liking, loving, and relationship satisfaction are used as covariates in the analyses of relationship status at Time 2.

\section{PROCEDURE}

Time 1. Groups of 2 to 12 participants attended two laboratory sessions scheduled 1 week apart. In the first session, they completed the card-sorting task to describe their partner and the measures of liking, loving, and relationship satisfaction. These were the only Time 1 measures used in the present study. ${ }^{1}$

Phone interview. The phone interview occurred about 1 year after Time 1. Participants were asked if their romantic relationship was ongoing $(64 \%)$ or had ended $(36 \%)$. They also responded to a series of questions about the relationship, including the items about relationship problems and conflict. At the end of the interview, participants were invited to the Time 2 laboratory session, for which they would be paid $\$ 15$. $^{2}$

Time 2. Groups of 2 to 8 participants completed the card-sorting task to describe their partner and the measures of liking, loving, and relationship satisfaction. If the relationship was ongoing, they were asked to describe their current perceptions of the partner or the relationship. If the relationship had ended, they were asked to describe their perceptions of the partner or the relationship approximately 1 month before the relationship ended.

\section{RESULTS}

Analyses of the Time 1 data conducted by Showers and Kevlyn (1999) focused on 99 of 118 participants who had complete data at Time 1. For the present analyses, 4 married individuals were excluded because their marital commitment might preclude change in relationship status. Five additional individuals could not be contacted at Time 2, leaving $n=90$ for analyses involving phone interview variables. For analyses involving variables from the Time 2 laboratory session, $n=65$ (23 out of 90 did not participate in the laboratory session and 2 had missing values for phi [the index of compartmentalization] because they included less than 2 negative attributes in their partner descriptions at Time 2). ${ }^{3}$

Table 1 presents the means, standard deviations, skewness, and intercorrelations for the measures used in the present analyses. Partner negativity (proportion of negative attributes) was arcsine transformed. In the following hierarchical regressions, all variables are centered for the purpose of testing interactions (Aiken \& West, 1991). There were no gender differences for any of the variables in Table 1 , ts $(88$ or 63$)<1.25$, ns.

\section{Partner Structure and Relationship Status at Time 2}

A logistic regression analysis tested whether partner structure at Time 1 predicted relationship status at Time 2. The criterion variable was relationship status (ongoing or ended). The predictors in the regression were the Time 1 measures of partner structure, partner negativity, and months in the relationship (the same predictors used by Showers and Kevlyn [1999] to predict liking and loving at Time 1) plus relationship conflict (the index of problems and conflicts experienced between Time 1 
TABLE 2: Hierarchical Logistic Regression of Likelihood of Ongoing Status Onto Partner Negativity, Relationship Conflict, Compartmentalized or Integrative Partner Structure at Time 1, Months in the Relationship, and Their Interactions

\begin{tabular}{|c|c|c|c|}
\hline \multirow[b]{2}{*}{ Predictors } & \multicolumn{3}{|c|}{ Likelihood of Ongoing Status } \\
\hline & $\begin{array}{c}\text { Cumulative } \\
\mathrm{R}^{2}\end{array}$ & $\begin{array}{l}\text { Increase } \\
\text { in } \mathrm{R}^{2} \quad B\end{array}$ & Wald \\
\hline Step 1 & $.27 * * *$ & $.27 * * *$ & \\
\hline Partner negativity & & -.61 & .11 \\
\hline Relationship conflict & & $-1.86^{* * *}$ & $13.93 * * *$ \\
\hline Partner structure & & -1.13 & .97 \\
\hline Months in relationship & & .43 & 1.67 \\
\hline Step 2 & $.35^{* *}$ & .08 & \\
\hline Negativity $\times$ Conflict & & -1.78 & .13 \\
\hline Negativity $\times$ Structure & & $22.21 *$ & $4.50 *$ \\
\hline Negativity $\times$ Months & & 3.42 & 1.38 \\
\hline Conflict $\times$ Structure & & -2.37 & .93 \\
\hline Conflict $\times$ Months & & -.12 & .02 \\
\hline Structure $\times$ Months & & .53 & .11 \\
\hline Step 3 & $.40 * *$ & .02 & \\
\hline \multicolumn{4}{|l|}{ Negativity $\times$ Conflict $\times$} \\
\hline Structure & & 14.05 & .30 \\
\hline \multicolumn{4}{|l|}{ Negativity $\times$ Conflict $\times$} \\
\hline Months & & .48 & .00 \\
\hline \multicolumn{4}{|l|}{ Negativity $\times$ Structure $\times$} \\
\hline & & -23.58 & 2.33 \\
\hline \multicolumn{4}{|l|}{ Conflict $\times$ Structure $\times$} \\
\hline Months & & -4.22 & .99 \\
\hline
\end{tabular}

NOTE: $R^{2}$ is computed by the Nagelkerke method. $N=90$.

$* p<.05 . * * p<.01 . * * * p<.001$.

and Time 2). The regression was set up hierarchically, with partner structure, partner negativity, months in the relationship, and conflict entered as main effects on Step 1; all two-way interactions of these variables were entered on Step 2; and all three-way interactions were entered on Step 3. Table 2 shows the results of this analysis. Significant effects were obtained for relationship conflict, Wald $=13.93, p<.001$, and the Negativity $\times$ Structure interaction, Wald $=4.50, p<.04$. In Figure 2 , the numbers in italics show the predicted values for the interaction. These values are superimposed on the line graphs for the results obtained by Showers and Kevlyn (1999) for a composite measure of liking and loving at Time 1. For participants who described their partner in relatively positive terms, a compartmentalized structure was associated with a greater likelihood of the relationship ending ( $45 \%$ ongoing) than was an integrative structure ( $80 \%$ ongoing; simple slopes test, Wald $=3.92$, $p<.05)$. This finding may illustrate the vulnerability of compartmentalized structures to the shifting salience of positive and negative beliefs, despite the fact that positive compartmentalization was correlated with greater liking and loving at Time 1.

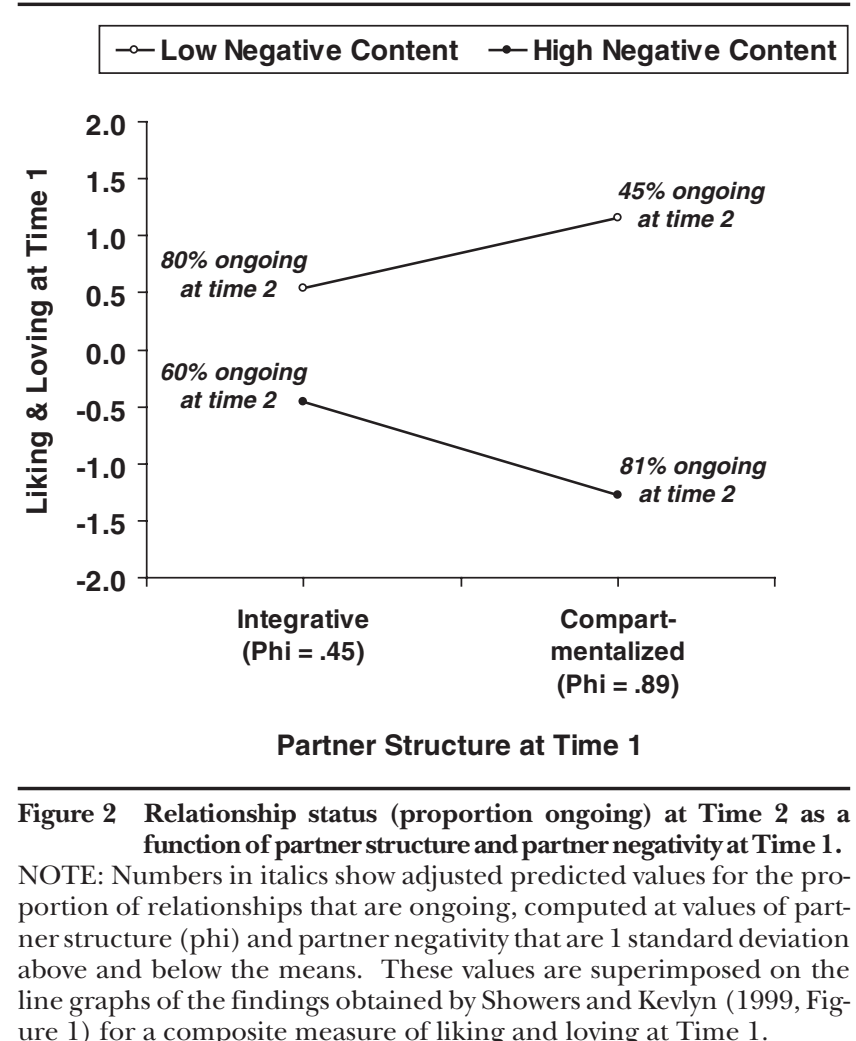

ure 1) for a composite measure of liking and loving at Time 1.

Among participants who described their partner in relatively negative terms, an integrative structure was associated with a greater likelihood of the relationship ending (60\% ongoing) than was a compartmentalized structure $(81 \%$ ongoing; simple slopes test, Wald $=1.36$, $n s)$. Thus, the apparent short-term advantage of negativeintegrative structures did not hold up for longer term outcomes, consistent with the view that the integrative process may wear itself out in time.

Follow-up analyses examined whether these outcome effects could be explained by attitudes toward the partner (liking, loving, or relationship satisfaction) at Time 1. Similar results were obtained when the analysis controlled for Time 1 liking and loving (Negativity $\times$ Structure interaction, Wald $=5.09, p<.03$ ) or relationship satisfaction (Negativity $\times$ Structure interaction, Wald $=3.65$, $p<.06){ }^{4}$

\section{Change in Partner Structure In Time}

These analyses tested the prediction of the dynamic model that people may shift to more integrative knowledge structures when negative attributes are salient (i.e., under conditions of stress or conflict). Specifically, we examined change in partner structure as a function of the perceived negativity of the partner and conflict experienced in the relationship during the course of the year. Change in partner structure was assessed by the change 
TABLE 3: Hierarchical Regression of Change in Partner Structure (Time 2 - Time 1) Onto Measures of Partner Negativity, Relationship Conflict, Compartmentalized or Integrative Partner Structure at Time 1, Months in the Relationship, and Their Interactions

\begin{tabular}{|c|c|c|c|c|}
\hline \multirow[b]{2}{*}{ Predictors } & \multicolumn{4}{|c|}{ Change in Partner Structure } \\
\hline & $\begin{array}{c}\text { Cumulative } \\
\mathrm{R}^{2}\end{array}$ & $\begin{array}{l}\text { Increase } \\
\text { in } \mathrm{R}^{2}\end{array}$ & $\mathrm{sr}^{2}$ & $\mathrm{sr}$ \\
\hline Step 1 & $.27 * * *$ & $.27 * * *$ & & \\
\hline Partner negativity & & & .00 & -.01 \\
\hline Relationship conflict & & & .00 & .01 \\
\hline Partner structure & & & $.24 * * *$ & $-.49 * * *$ \\
\hline Months in the relationship & & & .03 & .19 \\
\hline Step 2 & $.41 * * *$ & .14 & & \\
\hline Negativity $\times$ Conflict & & & $.10^{* *}$ & $.32 * *$ \\
\hline Negativity $\times$ Structure & & & .00 & -.01 \\
\hline Negativity $\times$ Months & & & $.05^{*}$ & $-.22 *$ \\
\hline Conflict $\times$ Structure & & & .00 & -.05 \\
\hline Conflict $\times$ Months & & & .00 & -.03 \\
\hline Structure $\times$ Months & & & .00 & .01 \\
\hline
\end{tabular}

NOTE: $s r=$ semipartial correlation; $s r^{2}=$ squared semipartial correlation coefficient (represents the proportion of variance uniquely accounted for by each predictor, beyond that accounted for by all other predictors at that step). The sign of srindicates the direction of the relation between each predictor and the dependent variable. $N=65$.

$* p<.05 . * * p<.01 . * * * p<.001$.

in phi from Time 1 to Time 2. The mean change in structure was very close to $0(M=-.01)$, with $15 \%$ of the cases falling more than $1 S D$ below the mean (increasing integration, $M=-.41$ ) and $15 \%$ of the cases falling more than $1 S D$ above the mean (increasing compartmentalization, $M=.25)$. The means for the high and low change groups indicate that individuals who experienced the greatest structural change were becoming more integrative in time. These cases dominate the main regression analysis, which examined change in structure as the criterion, with partner negativity, structure at Time 1, relationship conflict, months in the relationship, and their two-way interactions as predictors. (Structure at Time 1 was included to control for the possibility of regression to the mean; Cronbach \& Furby, 1970.) The results of this regression are shown in Table 3. Predicted values for the Negativity $\times$ Conflict interaction, $\beta=.36, p<.005$, are shown in Figure 3. Simple slopes tests found the slope of the regression lines at $1 S D$ above the mean of partner negativity and $1 S D$ below the mean of partner negativity to be significantly different from zero, $|\beta \mathrm{s}|>.37, p \mathrm{~s}<.03$. They indicate that the greatest change in structure occurred among individuals who had relatively negative perceptions of their partner yet experienced low conflict. Their partner structures became more integrative in time. The other "mixed" group-individuals with relatively positive perceptions of their partners and high conflict-also tended to become more integrative. The

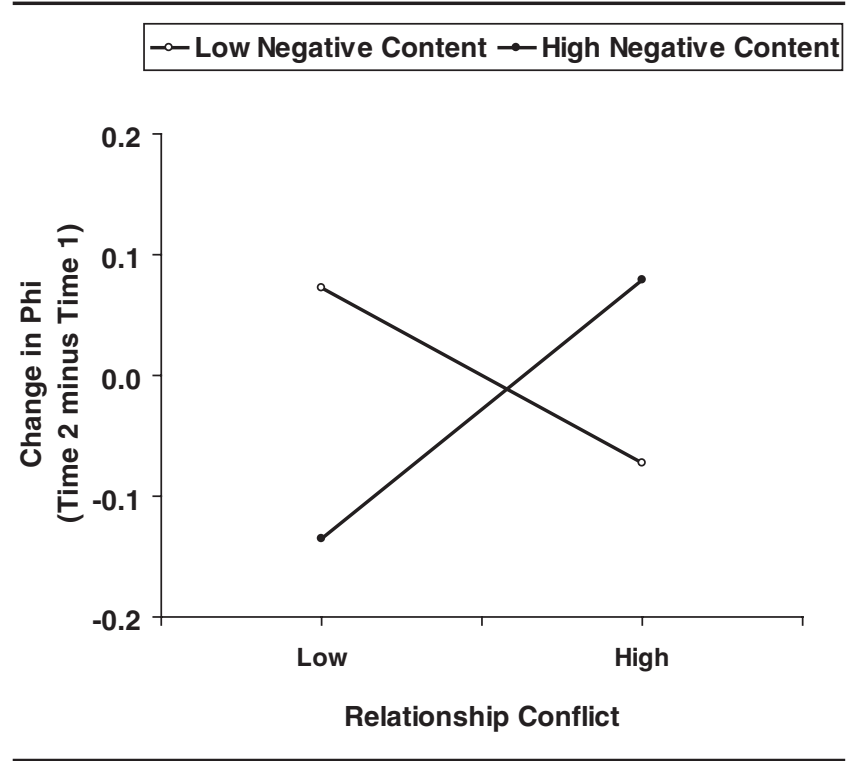

Figure 3 Change in partner structure (phi) from Time 1 to Time 2 under conditions of high or low relationship conflict.

NOTE: These are adjusted predicted values computed at values of conflict and partner negativity that are 1 standard deviation above and below the means.

two extreme groups (i.e., those with positive perceptions and low conflict and those with negative perceptions and high conflict) tended to become more compartmentalized. ${ }^{5}$

Another effect that emerged from this analysis was the Negativity $\times$ Months interaction, $\beta=-.24, p<.04$. Predicted values for this interaction revealed moderate amounts of structural change in individuals who had relatively positive perceptions of their partners. Those in newer relationships tended to become more integrative $(\mathrm{PV}=-.09)$, whereas those in older relationships tended to become more compartmentalized $(\mathrm{PV}=.09)$. This interaction accounted for very little structural change in individuals with negative perceptions of their partner $(\mathrm{PVs}=-.02,-.03)$.

\section{Change in Partner Structure and Relationship Status}

A follow-up analysis added change in partner structure to the initial regression for relationship status to test whether change in structure is uniquely associated with ongoing or ended outcomes. In a logistical hierarchical regression, relationship status (ongoing or ended) was the criterion variable. As in the initial regression, the predictors entered on Step 1 were the Time 1 measures of partner structure, partner negativity, relationship conflict, and months in the relationship; at Step 2, the significant interaction of Time 1 structure and partner negativity was entered and the nonsignificant two-way interactions were trimmed; on Step 3, change in struc- 
TABLE 4: Hierarchical Logistic Regression of Likelihood of Ongoing Status Onto Partner Negativity, Relationship Conflict, Compartmentalized or Integrative Partner Structure at Time 1, Change in Partner Structure (Time 2 - Time 1), and Interactions

\begin{tabular}{|c|c|c|c|c|}
\hline \multirow[b]{2}{*}{ Predictors } & \multicolumn{4}{|c|}{ Likelihood of Ongoing Status } \\
\hline & $\begin{array}{c}\text { Cumulative } \\
\mathrm{R}^{2}\end{array}$ & $\begin{array}{c}\text { Increase } \\
\text { in } \mathrm{R}^{2}\end{array}$ & $B$ & Wald \\
\hline Step 1 & $.33 * * *$ & $.33 * * *$ & & \\
\hline Partner negativity & & & 0.95 & 0.05 \\
\hline Relationship conflict & & & $-2.24 * * *$ & $12.70 * * *$ \\
\hline Partner structure & & & 0.30 & 0.04 \\
\hline Months in relationship & & & 0.31 & 0.57 \\
\hline Step 2 & $.39 * * *$ & .06 & & \\
\hline Negativity $\times$ Structure & & & 20.63 & 2.94 \\
\hline Step 3 & $.39 * * *$ & .00 & & \\
\hline Change in partner structure & & & -1.18 & 0.36 \\
\hline Step 4 & $.54 * * *$ & $.15^{*}$ & & \\
\hline \multicolumn{5}{|l|}{ Negativity $\times$ Change in } \\
\hline Structure & & & 37.43 & 1.69 \\
\hline Conflict $\times$ Change in Structur & ure & & $11.19 *$ & $4.59 *$ \\
\hline \multicolumn{5}{|l|}{ Structure $\times$ Change in } \\
\hline Structure & & & 17.73 & 1.72 \\
\hline Months $\times$ Change in Structur & & & -0.66 & 0.04 \\
\hline
\end{tabular}

NOTE: $R^{2}$ is computed by the Nagelkerke method. $n=65$. $* p<.05 . * * p<.01 . * * * p<.001$.

ture was entered; and on Step 4, the two-way interactions of change in structure with the Step 1 variables were entered. The regression results are presented in Table 4. The significant main effect for relationship conflict, Wald $=12.64, p<.001$, is qualified by an interaction with change in structure, Wald $=5.05, p<.03$. Predicted values for this interaction are shown in Figure 4. They indicate that a shift toward greater integration is associated with positive relationship outcomes (i.e., ongoing status), but only under conditions of low conflict (simple slopes test, Wald $=11.28, p<.01)$. Individuals who become more integrative under conditions of high conflict are most likely to break up. Even for this more complex model, the interaction of Time 1 structure with partner negativity obtained in the initial analysis is preserved in Step 4, Wald $=4.30, p<.04$. Moreover, both interactions remain significant when Time 1 liking, loving, and relationship satisfaction are controlled on Step 1: Conflict $\times$ Change in Structure, Wald $=4.10, p<.05$; Structure $\times$ Negativity, Wald $=4.32, p=.04 .^{6}$

Because the partner knowledge structure may be associated with feelings for the partner independent of relationship status, a follow-up analysis regressed liking at Time 2 onto the same set of predictors (partner structure, partner negativity, relationship conflict, months in the relationship, and change in structure) with Time 1 liking held constant and relationship status included as a moderator. However, because none of the two-way inter-

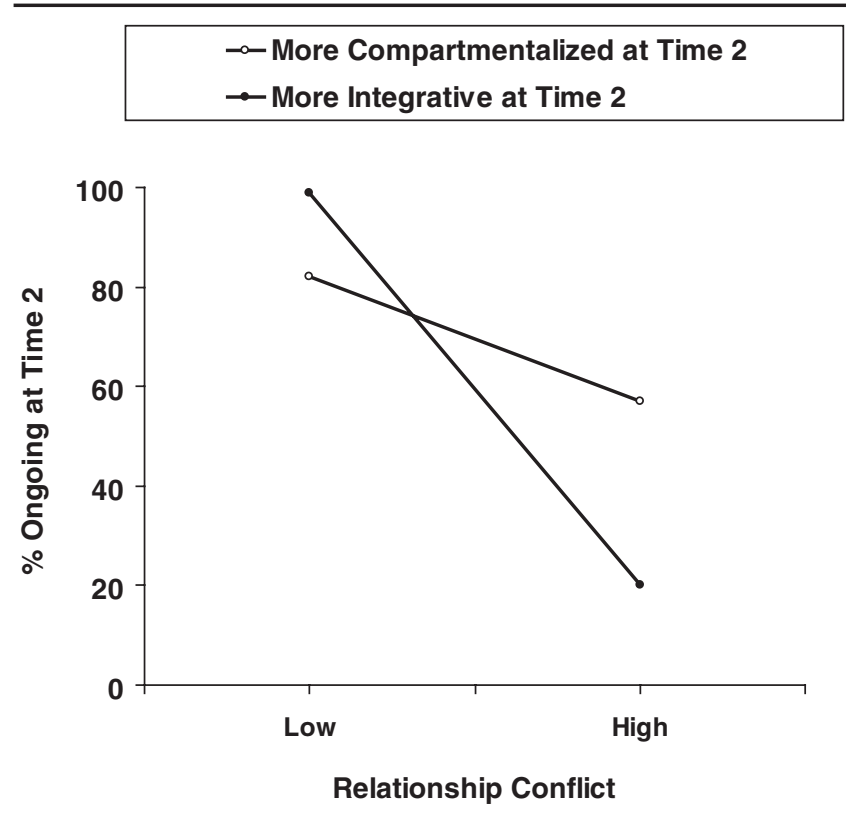

Figure 4 Relationship status (proportion ongoing) at Time 2 as a function of relationship conflict and change in partner structure.

NOTE: These are adjusted predicted values computed at values of relationship conflict and change in partner structure (phi) that are 1 standard deviation above and below the means.

actions involving relationship status were significant, these terms were trimmed from the model. In the final analysis, Step 1 entered the main effect terms for partner structure, partner negativity, relationship conflict, months in the relationship, relationship status, and Time 1 liking; Step 2 entered all two-way interactions of the first four terms; Step 3 entered change in structure; and Step 4 entered all two-way interactions of change in structure with the first four terms. There were significant main effects for Time 1 liking, relationship status, and conflict, $\beta \mathrm{s}>.24, p s<.02$. The Negativity $\times$ Change in Structure interaction was significant when entered alone on Step $4, \beta=.26, p<.04$. The predicted values for this interaction show an even more pronounced association between increased integration and a positive outcome (liking for the partner) for individuals with relatively positive perceptions of the partner $\left(\mathrm{PV}_{\text {inc int }}=89.0\right.$, $\mathrm{PV}_{\text {inc comp }}=78.5$ ). When perceptions of the partner were relatively negative, greater liking was associated with increased compartmentalization $\left(\mathrm{PV}_{\mathrm{inc}}\right.$ int $=75.6$, $\mathrm{PV}_{\text {inc comp }}=85.1$ ).

\section{DISCUSSION}

The findings of this study can be summarized as follows. First, the partner structures (positive compartmentalization and negative integration) that were associated with more positive feelings for partners at Time 1 were 
associated with higher rates of breakup 1 year later. Second, partner structures did change in time, such that integration increased for individuals who had negative perceptions of their partners or who were experiencing relationship conflict (but not both); compartmentalization increased when conflict and partner negativity were consistent. Third, increased integration was associated with ongoing status only when conflict was low. Individuals with negative-compartmentalized perceptions of their partners had low liking at Time 1, but those whose negative compartmentalization increased in time tended to be in ongoing relationships with relatively high liking (adjusted for partner negativity) at Time 2.

These findings can be interpreted in light of the literature on idealization and positive illusions in close relationships (Fletcher, Simpson, \& Thomas, 2000; Johnson \& Rusbult, 1989; Murray, Holmes, \& Griffin, 1996b). As part of that work, Murray and Holmes (1999) examined the use of integrative thinking in ongoing relationships. They found that the tendency to write integrative narratives about the relationship, and to link a partner's faults to their virtues, was associated with greater relationship satisfaction and stability. Moreover, they suggest that this sort of integrative thinking may help to create the positive illusions that are correlated with relationship success. Their interpretation is consistent with the present finding that positive integration is associated with ongoing status. Positive integration, similar to the integration observed by Murray and Holmes, may enhance perceptions of the partner. However, it may incorporate elements of both realism and illusion. Positive integration may be realistic in acknowledging both positive and negative partner attributes; it also may contribute to positive illusions if these attributes are processed with a positive bias (e.g., my partner only tends to get home late because she is so hardworking).

The fact that individuals who display negative integration do not have enhanced outcomes suggests that there are important boundaries on integration as an approach to relationship enhancement. Although negative integration may enhance perceptions of the partner in the short run, attempts to integrate important negative attributes may ultimately wear themselves out. More generally, integrative thinking may represent the willingness to devote cognitive resources to the struggle to minimize or resolve a partner's negative attributes. It is likely to be most advantageous when the individual has cognitive resources to spare (Showers \& Kling, 1996b), consistent with the present finding that increased integration was associated with a negative partner or high conflict, but not both. Although integration may reflect an attempt to minimize negative impacts, this struggle may not succeed, especially under conditions of high negativity or chronic conflict.
Somewhat surprising, the partner-enhancing strategy of positive compartmentalization was not associated with good long-term outcomes. Perhaps compartmentalization represents an attempt to ignore negative attributes, whereas integration leads to long-term resolution. However, Showers and Kevlyn's (1999) initial findings that positive compartmentalization was associated with the greatest liking and loving for the partner suggest that the relative virtues of compartmentalization and integration are context dependent. Perhaps positive compartmentalization is most advantageous when life is going smoothly and times are generally good. Under these circumstances, positive compartmentalization may help foster the starry-eyed illusions that keep relationships on the right foot, contribute to romance and intimacy, and establish fond memories that partners fall back on in difficult times. However, positive integrative structures may be more realistic in their acknowledgment of partner's flaws and they may therefore be more useful for handling the daily hassles and uplifts of a longterm relationship. This view is consistent with studies suggesting that some positive illusions may be difficult to maintain (Christensen \& Heavey, 1993; Kelly, Huston, \& Cate, 1985; Swann, De La Ronde, \& Hixon, 1994). Integrative partner structures also may provide resilience against challenges to the relationship that can be ameliorated by extra effort and attention to specific negative beliefs.

In other words, the disparate findings for the associations of partner structures with short-term feelings for the partner and long-term relationship outcomes may be best understood as an illustration of the need for flexibility in how we organize partner knowledge. Whereas one strategy enhances feelings in the short term, another may facilitate long-term outcomes. Moreover, transient events and circumstances may favor one structure instead of another at a given time. For example, some negative attributes may benefit from compartmentalization ("ill-tempered during February"), whereas others ("chain-smoker") may require the constant effort and attention of integration. Increases in integration were observed when relationship conflict or partner negativity was high (but not both). This suggests that integrative partner structures may reflect the struggle to resolve inconsistent beliefs and experiences (i.e., negative beliefs and low conflict, or positive beliefs and high conflict). When there is both high conflict and high negativity, there may be no point in struggling. In this case, increased compartmentalization, even if it maintains negative feelings, may be the path of least resistance and may even stabilize the relationship. Increased integration was only associated with longevity (i.e., ongoing status) when relationship conflict was low, suggesting that the integrative struggle does not always pay off (and, 
in fact, is more likely to pay off under benign conditions).

One of the most surprising results of this study was the stability of relationships of individuals who provided negative-compartmentalized descriptions of their partners at Time 1 (along with low liking and loving). These individuals not only were likely to stay with their partners but individuals whose negative compartmentalization increased with time had relatively positive feelings for their partner at Time 2 (taking the negativity of their prior perceptions into account). Showers and Kevlyn's (1999) suggestion that these are not especially happy, but stable, relationships, in which commitment may be maintained by external circumstances, is still plausible. The negative compartments they perceive ("my partner when he's out with his bowling buddies") may effectively isolate their relationship concerns even under conditions of high conflict.

If in fact knowledge structures are dynamic and people move flexibly among different structural configurations, then at least some of the partner structures observed at Time 1 represent transient responses to stress or internal events rather than stable baselines. The most extreme integrative or compartmentalized partner structures at Time 1 may represent transient responses to circumstances that may have changed by Time 2 . In this view, it is not surprising that structural change was observed. However, the fact that these changes were moderated by relationship conflict and partner negativity suggests that these are predictable fluctuations in structure rather than statistical artifact (i.e., regression to the mean). Note that Time 1 structure was included as a predictor in the analyses of the change scores. This technique helps to control for the possibility that change effects can be explained as regression to the mean (Cronbach \& Furby, 1970).

In the present study, partner negativity was the important moderator of the baseline relationship between partner structure and relationship outcomes (i.e., ongoing status and liking). In terms of the conceptual model, this means that the proportion of negative attributes in the partner card sort is the variable that best distinguishes individuals whose perception of their partner is basically positive (and for whom a positive-compartmen- talized structure should work well to enhance short-term feelings) from those whose partners have highly salient negative attributes that are difficult to compartmentalize. Studies of the self-concept have identified a different parameter-differential importance-as the critical moderator of the baseline relationship between selfstructure and mood or self-esteem (e.g., Showers, 1992). Differential importance is the relative importance (rated by the participant) of the positive and negative categories generated in the card sort (cf. Pelham \& Swann, 1989). Although differential importance for individuals' perceptions of their partner was included in preliminary analyses, it did not emerge as a significant moderator. Similar results were obtained by Showers and Kevlyn (1999). Both sets of findings suggest that in the case of partner descriptions, the proportion of negative attributes (rather than the relative importance of positive and negative partner aspects) is the best indicators of whether partners have negative attributes that will be difficult to compartmentalize.

To summarize, positive compartmentalization and negative integration may be most appropriately viewed as effective short-term strategies for enhancing feelings about either oneself or a romantic partner. Because compartmentalization may be vulnerable to shifts in the salience of negative attributes and negative integration may require excessive effort, rigid adherence to these styles of organization may not be optimal for an extended period of time. Instead, positive-integrative and negative-compartmentalized partner structures (and their more moderate feelings for the partner at Time 1) characterized individuals whose relationships were still ongoing 1 year later. Perhaps the best relationship strategy is the combined use of partner structures that enhance positivity in the short term, especially at the outset of the relationship, and those that maintain stability in the long term by buffering inevitable conflicts and emerging negative perceptions. In this view, people may move flexibly among compartmentalized and integrative styles of organizing partner beliefs to meet their current relationship needs, much as the dynamic model of self-organization calls for flexibility in the structure of self-knowledge (Showers \& Zeigler-Hill, 2003). 

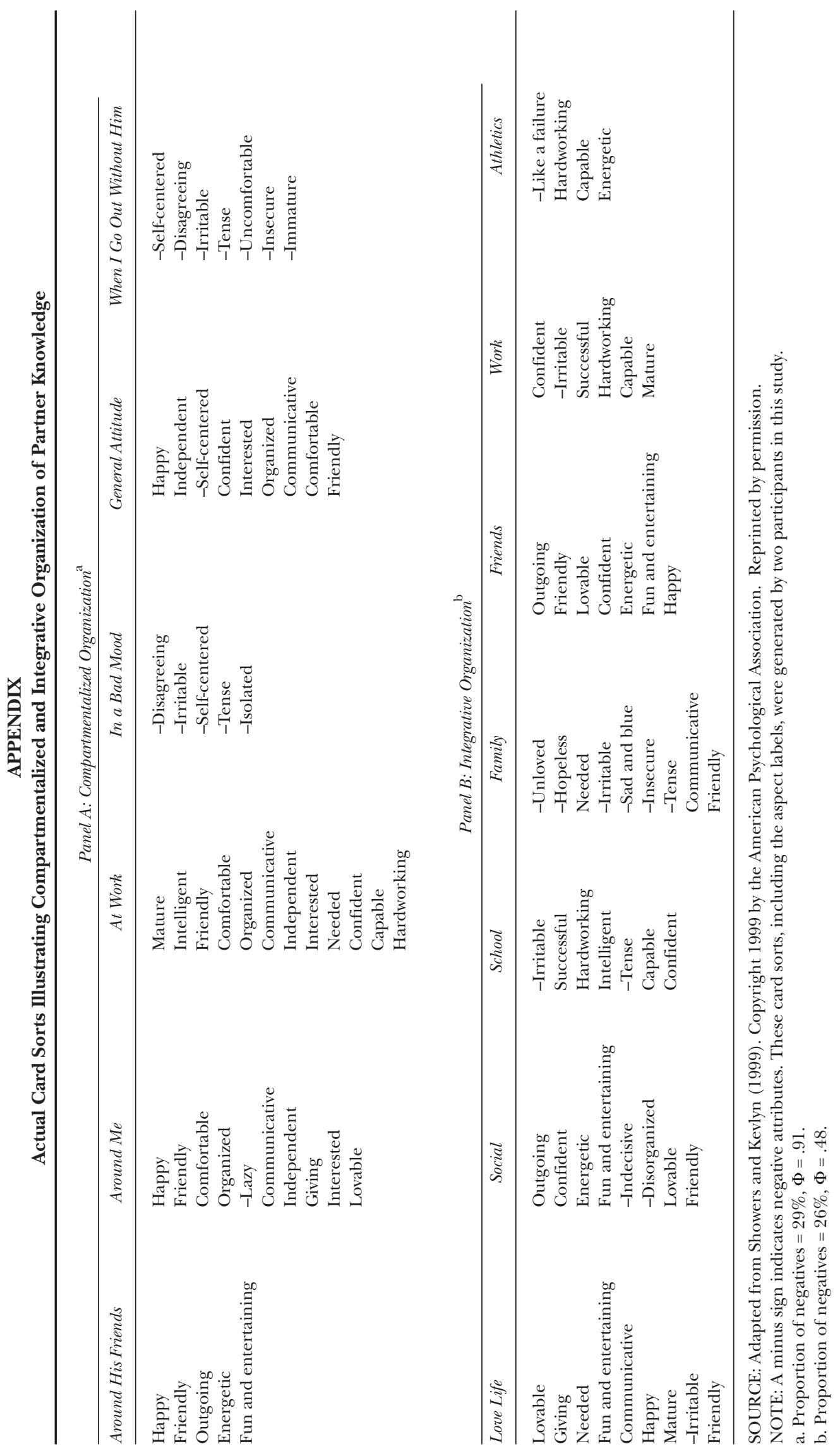


\section{NOTES}

1. Measures collected at Time 1 but not used in the present analyses included a self-descriptive card sort, attributions for partner behaviors, measures of relationship quality and accommodation responses, and several personality and mood measures. Findings for these measures are reported elsewhere (Amodio \& Showers, 2002; Showers \& Kevlyn, 1999).

2. The phone interview included eight items pertaining to relationship satisfaction, commitment, and stability that were not used in the present analyses.

3. $t$ tests were conducted to compare the sample analyzed at Time 2 $(n=65)$ to those cases whose data were excluded or missing $(n=34)$. Compared to those excluded or missing, individuals in the Time 2 sample were in less committed relationships (less likely to be married, engaged, or living together), $\chi^{2}(1)=6.48, p<.02$; reported less intimacy, $t(96)=2.28, p<.03$; and reported more conflict (arguing and anger), $t(90)=2.59, p<.02$. The Time 2 sample was also marginally more integrative in their partner structures, $t(97)=1.85, p<.07$.

4. Controlling for the Relationship Satisfaction $\times$ Structure interaction, Wald $=3.80, p=.051$, makes the Negativity $\times$ Structure interaction nonsignificant. This is not surprising given the correlation between partner negativity and relationship satisfaction, $r(90)=-.51, p<.001$. The patterns of the two interactions are very similar, such that individuals with high relationship satisfaction and integrative structures have the highest likelihood of ongoing status (94\%), whereas individuals with low relationship satisfaction and integrative structures have the lowest longevity (27\%).

5 . A similar Negativity $\times$ Conflict interaction for change in partner structure also emerged from the analysis of only those individuals whose relationships were still ongoing at Time $2(\exists=.67, p<.001, N=$ 41). The predicted values indicated a pronounced change toward increased integration for those individuals with negative perceptions of their partners and low conflict, consistent with the idea that people who are highly motivated to maintain their relationships engage in integrative thinking to make sense of a partner's negative attributes.

6 . Controlling for the Relationship Satisfaction $\times$ Structure interaction (see Note 4 ) leave the Conflict $\times$ Change in Structure interaction intact, Wald $=5.44, p<.02$.

\section{REFERENCES}

Aiken, L. S., \& West, S. G. (1991). Multiple regression: Testing and interpreting interactions. Newbury Park, CA: Sage.

Amodio, D. M., \& Showers, C. J. (2002). Similarity breeds liking" revisited: The moderating role of commitment. Unpublished manuscript.

Bower, G. H. (1981). Mood and memory. American Psychologist, 36, 129-148.

Bradbury, T. N., \& Fincham, F. D. (1990). Attributions in marriage: Review and critique. Psychological Bulletin, 107, 3-33.

Braiker, H. B., \& Kelley, H. H. (1992). Conflict in the development of close relationships. In S. Hendrick \& C. Hendrick (Eds.), Liking, loving, and relating. Pacific Grove, CA: Brooks/Cole.

Cate, R. M., Levin, L. A., \& Richmond, L. S. (2002). Premarital relationship stability: A review of recent research. Journal of Social and Personal Relationships, 19, 261-284.

Christensen, A., \& Heavey, C. L. (1993). Gender differences in marital conflict: The case of the demand/withdraw interaction pattern. In S. Oskamp \& M. Costanzo (Eds.), Gender issues in contemporary society (pp. 113-141). Newbury Park, CA: Sage.

Cramer, H. (1974). Mathematical methods of statistics. Princeton, NJ: Princeton University Press. (Original work published 1945)

Cronbach, L. J., \& Furby, L. (1970). How should we measure "change," or should we? Psychological Bulletin, 74, 68-80.

Everitt, B. S. (1977). The analysis of contingency tables. London: Chapman and Hall.

Fiske, S. T. (1982). Schema-triggered affect: Applications to social perception. In M. S. Clark \& S. T. Fiske (Eds.), Affect and cognition. Hillsdale, NJ: Lawrence Erlbaum.
Fletcher, G. J. O., Simpson, J. A., \& Thomas, G. (2000). Ideals, perceptions, and evaluations in early relationship development. Journal of Personality and Social Psychology, 79, 933-940.

Gottman, J. M., \& Krokoff, L. J. (1989). Marital interaction and satisfaction: A longitudinal view. Journal of Clinical and Consulting Psychology, 57, 47-52.

Halberstadt, J. B., \& Niedenthal, P. M. (1997). Emotional state and the use of stimulus dimensions in judgment. Journal of Personality and Social Psychology, 72, 1017-1033.

Hendrick, S. S. (1988). A generic measure of relationship satisfaction. Journal of Marriage and the Family, 50, 93-98.

Holmes, J. C., \& Murray, S. L. (1996). Conflict in close relationships. In E. T. Higgins \& A. W. Kruglanski (Eds.), Social psychology: Handbook of basic principles (pp. 622-654). New York: Guilford.

Huston, T. L., Caughlin, J. P., Houts, R. M., Smith, S. E., \& George, L. J. (1996). The connubial crucible: Newlywed years as predictors of marital delight, distress, and divorce. Journal of Personality and Social Psychology, 80, 237-252.

Johnson, D. J., \& Rusbult, C. E. (1989). Resisting temptation: Devaluation of alternative partners as a means of maintaining commitment in close relationships. Journal of Personality and Social Psychology, 57, 967-980.

Karney, B. R., \& Bradbury, T. N. (1995). The longitudinal course of marital quality and stability: A review of theory, method, and research. Psychological Bulletin, 118, 3-34.

Kelly, C., Huston, T. L., \& Cate, R. M. (1985). Premarital relationship correlates of the erosion of satisfaction in marriage. Journal of Social and Personal Relationships, 2, 167-178.

Linville, P. W. (1985). Self-complexity and affective extremity: Don't put all of your eggs in one cognitive basket. Social Cognition, 3, 94120.

Linville, P. W. (1987). Self-complexity as a cognitive buffer against stress-related illness and depression. Journal of Personality and Social Psychology, 52, 663-676.

McMahon, P. D., Showers, C. J., Rieder, S. L., Abramson, L. Y., \& Hogan, M. E. (2003). Integrative thinking and flexibility in the organization of self-knowledge. Cognitive Therapy and Research, 27, 167-184.

Murray, S. L., \& Holmes, J. G. (1999). The (mental) ties that bind: Cognitive structures that predict relationship resilience. Journal of Personality and Social Psychology, 77, 1228-1244.

Murray, S. L., Holmes, J. G., \& Griffin, D. W. (1996a). The benefits of positive illusions: Idealization and the construction of satisfaction in close relationships. Journal of Personality and Social Psychology, 70, 79-98.

Murray, S. L., Holmes, J. G., \& Griffin, D. W. (1996b). The selffulfilling nature of positive illusions in romantic relationships: Love is not blind, but prescient. Journal of Personality and Social Psychology, 71, 1155-1180.

Osgood, C. E. (1969). On the whys and wherefores of E, P, and A. Journal of Personality and Social Psychology, 12, 194-199.

Pelham, B. W., \& Swann, W. B., Jr. (1989). From self-conceptions to self-worth: On the sources and structure of global self-esteem. Journal of Personality and Social Psychology, 57, 672-680.

Rhodewalt, F., Madrian, J. C., \& Cheney, S. (1998). Narcissism, selfknowledge organization, and emotional reactivity: The effect of daily experiences on self-esteem and affect. Personality and Social Psychology Bulletin, 24, 75-87.

Riggs, D. S. (1993). Relationship problems and dating aggression: A potential treatment target. Journal of Interpersonal Violence, 8, 18-35.

Rubin, Z. (1970). Measurement of romantic love. Journal of Personality and Social Psychology, 16, 265-273.

Rusbult, C. E., Verette, J., Whitney, G. A., Slovik, L. F., \& Lipkus, I. (1991). Accommodation processes in close relationships: Theory and preliminary empirical evidence. Journal of Personality and Social Psychology, 60, 53-78.

Showers, C. (1992). Compartmentalization of positive and negative self-knowledge: Keeping bad apples out of the bunch. Journal of Personality and Social Psychology, 62, 1036-1049.

Showers, C. J. (1995). The evaluative organization of self-knowledge. In M. Kernis (Ed.), Efficacy, agency, and self-esteem (pp. 101-120). New York: Plenum. 
Showers, C. J. (2000). Self-organization in emotional contexts. In J. P. Forgas (Ed.), Feeling and thinking: The role of affect in cognition and judgments. Cambridge, UK: Cambridge University Press.

Showers, C. J. (2002). Integration and compartmentalization: A model of self-structure and self-change. In D. Cervone \& W. Mischel (Eds.), Advances in personality science (pp. 271-291). New York: Guilford.

Showers, C. J., \& Kevlyn, S. B. (1999). Organization of knowledge about a relationship partner: Implications for liking and loving. Journal of Personality and Social Psychology, 76, 958-971.

Showers, C. J., \& Kling, K. C. (1996a). The organization of self-knowledge: Implications for mood regulation. In L. L. Martin \& A. Tesser (Eds.), Striving and feeling: Interactions among goals, affect, and self-regulation (pp. 151-174). Mahwah, NJ: Lawrence Erlbaum.

Showers, C. J., \& Kling, K. C. (1996b). Organization of self-knowledge: Implications for recovery from sad mood. Journal of Personality and Social Psychology, 70, 578-590.
Showers, C. J., Limke, A., \& Zeigler-Hill, V. (2004). Self-structure and self-change: Applications to psychological treatment. Behavior Therapy, 35, 167-184.

Showers, C. J., \& Zeigler-Hill, V. (2003). Organization of selfknowledge: Features, functions, and flexibility. In M. R. Leary \& J. Tangney (Eds.), Handbook of self and identity (pp. 47-67). New York: Guilford.

Swann, W. B., Jr., De La Ronde, C., \& Hixon, J. G. (1994). Authenticity and positive strivings in marriage and courtship. Journal of Personality and Social Psychology, 66, 857-869.

Received September 14, 2002

Revision accepted July 21, 2003 